\title{
HUBUNGAN PENGGUNAAN KONTRASEPSI HORMONAL DENGAN KEJADIAN HIPERTENSI PADA WANITA USIA REPRODUKTIF (15-49 TAHUN) DI WILAYAH KERJA PUSKESMAS TELADAN KOTA MEDAN TAHUN 2019
}

\author{
Manik, Risda Mariana ${ }^{1 *}$, Ambarita, Bernadetta ${ }^{2}$ \\ ${ }^{1,2}$ Dosen Program Studi D3 Kebidanan STIKes Santa Elisabeth Medan \\ *Korespondensi: risda.mariana@gmail.com
}

\begin{abstract}
Background: The prevalence of hypertension in Indonesia continues to increase, especially in women. The incidence rate reached $28.8 \%$ higher than the incidence of hypertension in men which is $22.8 \%$. There are factors that make women more at risk of hypertension than men. Namely the use of hormonal contraception in women whose users reach $47.54 \%$. Purpose: to analysis Correlational hormonal contraceptive use and hypertension. Methods: This research is an observational survey research, case-control design. Held in the Work Area of the Medan City Primary Health Center. Conducted from March-June 2019. The population were all women of productive age (15-49 years) totaling 572 people. The size of the case sample was 35 people and 35 controls. Case samples were taken by means of consecutive sampling, control samples were taken by convenient sampling. Data analysis was performed univariately and bivariately using the Chi Square statistical test $\left(\chi^{2}\right)$ with a significance level of 0.05 . Results: In the hypertension group, $77.1 \%$ used hormonal contraception and $22.9 \%$ did not use hormonal contraception. Whereas in the non hypertensive group $62.9 \%$ did not use hormonal contraception only $37.1 \%$ used hormonal contraception. There is a relationship between hormonal contraceptive use and hypertension in women of reproductive age. A value $(\mathrm{OR}=$ 5.7; 95\% CI 2,008-16,244) means that women of reproductive age are at risk of experiencing hypertension 5.7 times greater if women of reproductive age use hormonal contraception than those who do not use hormonal contraception. Conclusion: Women of reproductive age are at risk of developing hypertension when using hormonal contraception. Therefore, it is recommended that women of reproductive age prefer non-hormonal contraception or natural contraception. If using hormonal contraception to keep monitoring blood pressure regularly at least 3 months after using hormonal contraception and immediately stop using hormonal contraception if there is a hypertension
\end{abstract}

Keyword: Hormonal contraception; Hypertension; Women at Reproductive age 


\begin{abstract}
ABSTRAK
Latar Belakang: Prevalensi hipertensi di Indonesia terus meningkat, terutama pada wanita. Angka kejadiannya mencapai $28,8 \%$ lebih tinggi dari angka kejadia hipertensi pada pria yaitu $22,8 \%$. Ada faktor yang membuat wanita lebih beresiko mengalami hipertensi daripada pria. Yakni penggunaan kontrasepsi hormonal pada wanita yang jumlah pengguna nya mencapai $47,54 \%$. Tujuan Penelitian: untuk mengetahui hubungan penggunaan kontrasepsi hormonal dengan kejadian hipertensi. Metode: Penelitian ini merupakan jenis penelitian survei observasional, rancangan case-control. Dilaksanakan di Wilayah Kerja Puskesmas Teladan Kota Medan. Dilakukan mulai bulan Maret-Juni 2019. Populasi pada penelitian ini seluruh wanita usia reproduktif (15-49 tahun) yang berjumlah 572 orang. Besarnya sampel kasus 35 orang dan kontrol 35 orang. Sampel kasus diambil dengan cara Consecutive sampling, sampel kontrol diambil secara Convenient sampling. Analisis data dilakukan secara univariat dan bivariat menggunakan uji statistik $C h i$ Square $\left(\chi^{2}\right)$ dengan tingkat kemaknaan 0,05. Hasil: Pada kelompok hipertensi, 77,1 $\%$ menggunakan kontrasepsi hormonal dan 22,9\% tidak menggunakan kontarsepsi hormonal. Sedangkan pada kelompok tidak hipertensi 62,9\% tidak menggunakan kontrasepsi hormonal hanya 37,1\% menggunakan kontrasepsi hormonal. Ada hubungan penggunaan kontrasepsi hormonal dengan kejadian hipertensi pada wanita usia reproduktif. Diperoleh nilai $(\mathrm{OR}=5,7$; 95\%CI 2,008-16,244) artinya bahwa wanita usia reproduktif beresiko mengalami hipertensi 5,7 kali lebih besar jika wanita usia reproduktif menggunakan kontrasepsi hormonal dibanding yang tidak menggunakan kontrasepsi hormonal. Simpulan: Wanita usia reproduktif beresiko mengalami hipertensi jika menggunakan kontrasepsi hormonal. Oleh karena itu, disarankan kepada wanita usia reproduktif agar membatasi pemakaian awal kontrasepsi hormonal dan lebih memilih kontrasepsi non hormonal ataupun kontrasepsi alamiah. Jika menggunakan kontrasepsi hormonal agar tetap melakukan monitoring tekanan darah secara rutin minimal 3 bulan pasca penggunaan kontrasepsi hormonal dan segera menghentikan pemakaian kontrasepsi hormonal jika mengalami hipertensi.
\end{abstract}

Kata Kunci: Kontrasepsi Hormona; Hipertensi; Wanita Usia Reproduktif

\title{
PENDAHULUAN
}

Menurut Depkes RI (2015), wanita usia subur adalah wanita yang masih dalam usia reproduktif yaitu antara 15-49 tahun. Wanita usia reproduktif mempunyai organ reproduksi yang masih berfungsi dengan baik. Masa reproduksi sehat wanita dibagi menjadi 3 periode yaitu reproduksi muda (15-19 tahun) merupakan tahap menunda kehamilan, reproduksi sehat (20-35 tahun) merupakan tahap untuk menjarangkan kehamilan, dan reproduksi tua (36-49 tahun) merupakan 
tahap untuk mengakhiri kehamilan. Agar dapat mencapai hal tersebut maka pemerintah membuat program Keluarga Berencana (KB).

Keluarga Berencana (KB) merupakan upaya mengatur kehamilan, kelahiran anak, jarak dan usia ideal melahirkan. Pengaturan kehamilan dalam program KB dilakukan dengan menggunakan alat kontrasepsi. Penggunaan kontrasepsi di Indonesia meningkat setiap tahunnya. Tingginya cakupan wanita usia 15-49 tahun yang melakukan KB sejalan dengan menurunnya angka fertilitas nasional.

Dilihat dari jenis kelamin, metode kontrasepsi perempuan yang digunakan jauh lebih besar dibanding dengan metode kontrasepsi laki-laki. Metode kontrasepsi perempuan sebesar 93,66\% sementara laki-laki hanya sebesar 6,34\%. Data pada profil kesehatan Indonesia (2014) juga menunjukkan, wanita adalah aseptor KB yang jumlahnya lebih banyak daripada pria. Sebanyak 59,3\% wanita usia subur menggunakan kontrasepsi modern. Kontrasepsi yang paling diminati adalah kontrasepsi hormonal, yakni 47,54\% suntikan dan 23,58\% pil (Kemenkes RI, 2015).

Suntikan dan pil merupakan alat kontrasepsi yang paling banyak dipilih oleh wanita karena dianggap lebih mudah, praktis dan aman. Saifuddin, A.B (2016), menyatakan bahwa kekhawatiran utama pemakaian metode kontrasepsi hormonal adalah peningkatan risiko penyakit sistem kardiovaskuler, terutama keluhan kesehatan terhadap obesitas dan hipertensi. Penggunaan kontrasepsi yang mengandung hormon estrogen dan progesteron dapat menyebabkan terjadinya peningkatan tekanan darah, karena terjadinya hipertropi jantung dan peningkatan respon presor angiotensin II dengan melibatkan jalur renin angiotensin system. (Olatunji, L.A dan Saldove, A.O., 2012).

Hasil penelitian White, K., et al (2013) di El Paso (Texas), menemukan 7\% pengguna kontrasepsi suntikan dan $10,5 \%$ pengguna oral kontrasepsi mengalami hipertensi. Nojomi, M., et al (2013) menemukan 31,5\% wanita Iran yang menggunakan kontrasepsi mengalami hipertensi. Murayama, M., et al (2013) yang melakukan penelitian di Thailand juga menemukan bahwa wanita yang menggunakan kontrasepsi pil memiliki tekanan darah lebih tinggi daripada wanita yang tidak pernah menggunakannya. 
Penelitian Lestari, P.I., dkk di Padang (2013) menyatakan bahwa wanita yang menggunakan kontrasepsi hormonal 2,95 kali beresiko terkena hipertensi. Gaby, G.L., dkk (2012) juga menyatakan bahwa ada hubungan antara penggunaan pil KB dengan hipertensi pada WUS di Kecamatan Tombariri. Wanita usia subur pengguna pil KB 17,2 kali berisiko terkena hipertensi daripada WUS yang tidak menggunakan pil KB.

Sebuah penelitian yang menggunakan data Riskesdas 2013 juga memberi kesimpulan bahwa wanita usia 15-49 tahun yang menggunakan kontrasepsi pil kemungkinan beresiko 1,38 kali lebih besar untuk mengalami kejadian hipertensi dibandingkan dengan wanita usia 15-49 tahun yang tidak menggunakan kontrasepsi pil (L. Pangaribuan dan D. Lolong., 2015).

Hipertensi merupakan salah satu penyebab utama mortalitas dan morbiditas di Indonesia. Hipertensi dalam jangka waktu yang lama dan tanpa penanganan dapat menimbulkan kerusakan pada ginjal, jantung dan otak. Hipertensi merupakan silent killer dimana gejala dapat bervariasi pada masing-masing individu dan hampir sama dengan gejala penyakit lainnya. Hipertensi juga merupakan salah satu faktor pemicu penyakit tidak menular (Non Communicable Disease $=$ NCD) seperti penyakit jantung dan stroke yang merupakan penyebab kematian utama di dunia (Kemenkes RI, 2013).

Hipertensi juga merupakan faktor risiko independen untuk penyakit kardiovaskuler pada wanita. Penyakit kardiovaskuler merupakan pembunuh utama para wanita saat ini, yaitu 1 dari setiap 2,5 kematian. Berdasarkan survey oleh National Health and Nutrition Examination Survey dari tahun 1999-2000, sekitar $60 \%$ wanita dengan hipertensi sudah diobati namun hanya sepertiganya yang dapat terkontrol (Mashitah, S.I dan Romdoni, R., 2015).

Sebuah penelitian oleh Moser, A.K., et al (2014) di India menunjukkan bahwa wanita (26\%) lebih banyak menderita hipertensi daripada pria (22\%). Prevalensi hipertensi juga meningkat di banyak kawasan Asia Selatan, termasuk Nepal. Rotermann, A., et al (2015) menyatakan faktor resiko hipertensi dan prehipertensi pada wanita dewasa pedesaan juga meningkat. Hipertensi merupakan salah satu faktor resiko utama untuk penyakit kardiovaskular di kawasan ini. 
Sebuah penelitian pada 13.638 wanita berusia lebih dari 16 tahun, diperoleh hasil bahwa 33,3\% mengalami hipertensi dan $14,4 \%$ pre hipertensi.

Berdasarkan data Riskesdas 2013, prevalensi hipertensi di Indonesia adalah sebesar 26,5\%. Prevalensi hipertensi pada wanita cenderung lebih tinggi dari pria yaitu 22,8\% untuk pria dan Wanita 28,8\%. Prevalensi hipertensi pada usia 18 tahun ke atas berdasarkan hasil pengukuran sebesar 31,7\%, pada perempuan sebesar 31,9\% dan laki-laki 31,3\%. Prevalensi berdasarkan umur usia 15-24 tahun 8,7\%, usia 24-34 tahun 14,7\% dan 35-44 tahun 24,8\%. Pada umumnya penderita hipertensi berusia lebih dari 40 tahun, namun pada saat ini tidak menutup kemungkinan penderita pada usia yang lebih muda (Kemenkes RI, 2013).

Pada profil Kota Medan tahun 2017 ditemukan jumlah peserta akseptor KB aktif meningkat dari 62,2\% (2013) menjadi 73,3\% (2014). Jenis kontrasepsi yang paling banyak digunakan oleh peserta KB aktif di tahun 2016 adalah kontrasepsi suntik (34,9\%) dan paling sedikit MOP (1\%). Demikian juga untuk peserta KB baru, akseptor lebih menyukai suntik (41\%) dan paling sedikit memilih MOP $(1,3 \%)$ sementara untuk penyakit hipertensi menduduki peringkat kedua dari 10 penyakit terbanyak pasien rawat jalan di puskesmas sejak tahun 2012-2014.

Berdasarkan Profil Kota Medan, jumlah kejadian hipertensi pada wanita paling banyak ditemukan di Puskesmas Teladan Kota Medan yakni 12,8\%, diikuti oleh Puskesmas Medan Denai 6,31\% dan puskesmas Medan Johor 4,21\%. Sedangkan untuk kejadian obesitas pada wanita paling banyak ditemukan di Puskesmas Teladan 67\%, diikuti dengan Puskesmas Medan Tuntungan 64\% dan Puskesmas Medan Amplas 63\%. Sedangkan untuk akseptor KB mayoritas di puskesmas ini adalah wanita yakni 73,3\% dan jenis kontrasepsi yang paling banyak digunakan adalah $34,9 \%$ suntik, dan $30,5 \%$ pil.

Penelitian ini bertujuan untuk menganalisis hubungan antara penggunaan kontrasepsi hormonal dengan kejadian hipertensi pada wanita usia reproduktif (1549 tahun) di Wilayah Kerja Puskesmas Teladan Kota Medan tahun 2019. 


\section{METODE}

Penelitian ini merupakan jenis penelitian survei observasional, rancangan dalam penelitian ini Case-Control. Penelitian ini dilaksanakan di Wilayah Kerja Puskesmas Teladan Kota Medan. Pemilihan tempat ini berdasarkan Profil Kesehatan Kota Medan ditemukan jumlah kejadian hipertensi pada wanita paling banyak di Puskesmas Teladan. Pada Profil Puskesmas Teladan 2017 diketahui bahwa hipertensi adalah nomor 3 penyakit terbanyak di puskesmas ini, yakni 18,06\%. Waktu penelitian dilakukan mulai bulan Maret-Juni 2019. Populasi pada penelitian ini adalah seluruh wanita usia reproduktif (15-49 tahun) di Wilayah Kerja Puskesmas Teladan Kota Medan yang berjumlah 572 orang. Populasi kasus adalah wanita usia reproduktif (15-49 tahun) menderita hipertensi sebanyak 52 orang. Populasi kontrol dalam penelitian ini adalah wanita usia reproduktif (15-49 tahun) di Wilayah Kerja Puskesmas Teladan Kota Medan yang tidak menderita hipertensi sebanyak 480 orang. Sampel dalam penelitian ini adalah sebagian wanita usia reproduktif (15-49 tahun) di wilayah kerja Puskesmas Teadan Kota Medan. Kriteria Inklusi sampel:responden menetap di Wilayah Kerja Puskesmas Teladan Kota Medan, sudah menikah, sehat jasmani dan rohani. Kriteria eksklusi sampel: responden merokok dan minum alkohol, menderita hipertensi dengan penyakit penyerta seperti ginjal dan diabetes mellitus, sedang hamil ataupun menyusui. Sampel kontrol dalam penelitian ini adalah sebagian wanita usia subur (15-49 tahun) di Wilayah Kerja Puskesmas Teladan Kota Medan yang tidak sedang menderita hipertensi. Besarnya sampel yang diambil pada studi kasus kontrol dihitung dengan menggunakan rumus dari: Stanley Lameshow et.al (1997), yaitu :

$$
n=\frac{\left(Z_{1-a / 2} \sqrt{2 P_{2}\left(1-P_{2}\right)}+Z_{1-\beta} \sqrt{P_{1}\left(1-P_{1}\right)+P_{2}\left(1-P_{2}\right)}\right)^{2}}{\left(P_{1}-P_{2}\right)^{2}}
$$

Dari perhitungan diperoleh sampel sebanyak 35 orang dengan perbandingan kasus kontrol 1:1, sehingga jumlah sampel dan kontrol sebanyak 70 orang. Sampel kasus adalah wanita usia 15-49 tahun yang menderita hipertensi yakni tekanan darah sistolik $\geq 140 \mathrm{mmHg}$ dan diastolik $\geq 90 \mathrm{mmHg}$ yang diperoleh dari data rekam medik Puskesmas Teladan. Sampel diambil dengan cara Consecutive sampling, semua subyek yang terdata di rekam medik secara berurutan dan 
memenuhi kriteria pemilihan dimasukkan dalam penelitian sampai jumlah subjek mencapai 35 sampel kemudian dilakukan pengukuran tekanan darah dan pengisian kuesioner dengan mendatangi alamat sampel. Sampel kontrol adalah wanita usia subur 15-49 tahun yang tidak menderita hipertensi yakni tekanan darah sistolik $\leq$ $140 \mathrm{mmHg}$ dan diastolik $\leq 90 \mathrm{mmHg}$. Sampel kontrol diambil secara Convenient sampling, sampel diambil tanpa sistematika tertentu, yakni yang dapat ditemukan disekitar tempat tinggal masing-masing sampel kasus untuk dilakukan pengukuran tekanan darah dan pengisian kuesioner. Data pada penelitian ini terdiri dari data penggunaan kontarsepsi Hormonal ( Ya, jika memiliki riwayat atau sedang menggunakan pil, atau suntikan, atau implant dan Tidak, jika memiliki riwayat menggunakan alat kontrasepsi non hormonal. Data Hipertensi (Hipertensi jika TD sistolik dan/ atau diastolik $\geq 140 / 90 \mathrm{mmHg}$ dan Tidak Hipertensi jika TD < 140/90 $\mathrm{mmHg}$ ). Analisis data dilakukan secara univariat untuk memperoleh gambaran variabel independen yang meliputi penggunaan kontrasepsi hormonal dan analisis bivariat untuk menguji ada tidaknya hubungan penggunaan penggunaan kontrasepsi hormonal dengan kejadian hipertensi menggunakan uji statistik Chi Square $\left(\chi^{2}\right)$ dengan tingkat kemaknaan 0,05 .

\section{HASIL}

Tabel 1 menunjukkan bahwa pendidikan wanita usia reproduktif di wilayah kerja Puskesmas Teladan pada umumnya sama dengan wilayah lainnya di Kota Medan yakni pendidikan menengah. Masih terdapat wanita usia reproduktif yang berpendidikan rendah didaerah ini dikarenakan banyak perantau yang datang dari daerah lain untuk melanjutkan pendidikan dan terjebak dalam pergaulan bebas pada masa remaja sehingga menyebabkan sebagian dari mereka harus menghentikan pendidikannya, namun ada juga yang datang merantau untuk mencari pekerjaan karena ketidakmampuan orangtua untuk menyekolahkan mereka. Dari segi pekerjaan wanita usia reproduktif didaerah ini umumnya bekerja membantu suami memenuhi kebutuhan rumah tangga dengan jenis pekerjaan yang bervariasi. Sebagian bekerja sebagai karyawan swasta, pekerja lepas, dan berdagang. Hal ini 
dikarenakan kebutuhan hidup yang cukup tinggi namun pendapatan suami tidak mencukupi untuk memenuhi kebutuhan tersebut.

Tabel 1 Distribusi Frekuensi Karakteristik Wanita Usia Reproduktif (15-49 tahun) di Wilayah Kerja Puskesmas Teladan Kota Medan Tahun 2019

\begin{tabular}{lcccc}
\hline \multirow{2}{*}{\multicolumn{1}{c}{ Karakteristik }} & \multicolumn{4}{c}{ Wanita Usia Reproduktif } \\
\cline { 2 - 5 } & \multicolumn{2}{c}{ Hipertensi } & \multicolumn{2}{c}{ Tidak Hipertensi } \\
\cline { 2 - 5 } Umur & & \% & n & \% \\
20-35 tahun & 13 & 37 & 17 & 49 \\
$<20$ tahun dan >35 tahun & 22 & 63 & 18 & 51 \\
\hline Pendidikan & & & & \\
Rendah (SD,SMP) & 5 & 14,3 & 10 & 28,6 \\
Menengah (SMA/SMK) & 19 & 54,3 & 21 & 60,0 \\
Tinggi (D-III/S-I/S2/S3) & 11 & 31,4 & 4 & 11,4 \\
\hline Pekerjaan & & & & \\
IRT & 15 & 42,9 & 13 & 37,1 \\
Wiraswasta & 14 & 40,0 & 20 & 57,2 \\
PNS & 6 & 17,1 & 2 & 5,7 \\
\hline Total & 35 & 100 & 35 & 100 \\
\hline
\end{tabular}

Tabel 2 menunjukkan bahwa wanita usia reproduktif di wilayah ini memiliki minat yang tinggi terhadap penggunaan kontrasepsi hormonal. Pada kelompok hipertensi, 77,1 \% menggunakan kontrasepsi hormonal dan 22,9\% tidak menggunakan kontarsepsi hormonal. Sedangkan pada kelompok tidak hipertensi $62,9 \%$ tidak menggunakan kontrasepsi hormonal hanya $37,1 \%$ menggunakan kontrasepsi hormonal.

Tabel 2 Distribusi Frekuensi Penggunaan Kontrasepsi Hormonal di Wilayah Kerja Puskesmas Teladan Kota Medan Tahun 2019

\begin{tabular}{lcccc}
\hline \multirow{2}{*}{$\begin{array}{c}\text { Penggunaan } \\
\text { Kontrasepsi }\end{array}$ Hormonal } & \multicolumn{3}{c}{ Wanita Usia Reproduktif } \\
\cline { 2 - 5 } \multicolumn{1}{c}{ Hipertensi } & \multicolumn{2}{c}{ Tidak Hipertensi } \\
\hline Menggunakan & $\mathbf{n}$ & $\mathbf{\%}$ & $\mathbf{n}$ & \% \\
Tidak Menggunakan & 27 & 77,1 & 13 & 37,1 \\
\hline Total & 8 & 22,9 & 22 & 62,9 \\
\hline
\end{tabular}

Tabel 3 menunjukkan bahwa hasil uji statistik diperoleh nilai $(p=0,002)$ artinya ada hubungan penggunaan kontrasepsi hormonal dengan kejadian hipertensi pada wanita usia reproduktif. Dari hasil analisis juga diperoleh nilai $(\mathrm{OR}=5,7$; 95\% CI 2,008-16,244) artinya bahwa wanita usia reproduktif beresiko mengalami 
hipertensi 5,7 kali lebih besar jika wanita usia reproduktif menggunakan kontrasepsi hormonal dibanding yang tidak menggunakan kontrasepsi hormonal.

Tabel 3 Hubungan Penggunaan Kontrasepsi Hormonal Dengan Kejadian Hipertensi Pada Wanita Usia Reproduktif (15-49 Tahun) di Wilayah Kerja Puskesmas Teladan Kota Medan Tahun 2019

\begin{tabular}{|c|c|c|c|c|c|c|c|c|}
\hline \multirow{3}{*}{$\begin{array}{c}\text { Penggunaan } \\
\text { Kontrasepsi } \\
\text { Hormonal }\end{array}$} & \multicolumn{4}{|c|}{ Wanita Usia Reproduktif } & \multirow{3}{*}{$\underset{\text { value }}{p}$} & \multirow{3}{*}{ OR } & \multirow{2}{*}{\multicolumn{2}{|c|}{$95 \% \mathrm{CI}$}} \\
\hline & \multicolumn{2}{|c|}{ Hipertensi } & \multicolumn{2}{|c|}{$\begin{array}{c}\text { Tidak } \\
\text { Hipertensi }\end{array}$} & & & & \\
\hline & $\mathbf{n}$ & $\%$ & $\mathbf{n}$ & $\%$ & & & Lower & Upper \\
\hline Menggunakan & 27 & 77,1 & 13 & 37,1 & & & & \\
\hline $\begin{array}{l}\text { Tidak } \\
\text { Menggunakan }\end{array}$ & 8 & 22,9 & 22 & 62,9 & 0,002 & 5,7 & 2.008 & 16,244 \\
\hline Total & 35 & 100 & 35 & 100 & & & & \\
\hline
\end{tabular}

\section{PEMBAHASAN}

Pada penelitian ini, jumlah sampel sebanyak 70 orang yang terdiri dari 35 kelompok kasus dan 35 kelompok kontrol. Dari kelompok kasus yakni wanita usia reproduktif yang menderita hipertensi ditemukan $63 \%$ kejadian hipertensi terdapat pada kelompok umur $<20$ tahun dan $>35$ tahun, 54,3\% pada kelompok pendidikan menegah, dan 42,9\% pada kelompok Ibu Rumah Tangga (IRT).

Tekanan darah sistolik meningkat progresif sesuai usia dan orang lanjut usia dengan hipertensi merupakan resiko besar untuk penyakit kardiovaskular. Prevalensi hipertensi meningkat sesuai dengan usia. Pendidikan yang mayoritas menengah pada wanita usia reproduktif juga berkontribusi dalam kemampuan wanita mengambil keputusan untuk menghindari faktor resiko lainnya yang dapat menyebabkan hipertensi seperti penggunaan KB hormonal, pemilihan makanan yang memicu terjadinya hipertensi ataupun pemilihan makanan yang dapat mencegah penyakit hipertensi. Pada IRT seharusnya memiliki kesempatan yang lebih banyak untuk melakukan aktivitas fisik yang dapat membakar kalori, namun kecanggihan zaman dan ketersediaan alat elektronik yang dapat diperoleh dengan harga terjangkau menjadikan IRT memiliki waktu yang banyak untuk beristirahat dan melakukan aktivitas harian tanpa mengeluarkan banyak energi.

Berdasarkan hasil analisis bivariat menunjukkan ada hubungan penggunaan kontrasepsi hormonal dengan kejadian hipertensi pada wanita usia reproduktif 
$(p=0,002)$. Demikian juga dengan $\mathrm{OR}=5,7$ menunjukkan bahwa wanita usia reproduktif beresiko mengalami hipertensi 5,7 kali lebih besar jika wanita usia reproduktif menggunakan kontrasepsi hormonal dibanding yang tidak menggunakan kontrasepsi hormonal.

Penelitian ini sejalan dengan penelitian Isfandri, S (2015), pada penelitian ini didapatkan hasil bahwa terdapat hubungan bermakna antara penggunaan alat kontrasepsi terhadap kejadian hipertensi. Demikian juga dengan penelitian Lestari, P.I., dkk (2013) diperoleh hasil bahwa ibu yang menggunakan kontrasepsi hormonal > 2 tahun memiliki peluang 2,954 kali menderita hipertensi dibandingkan dengan ibu yang menggunakan kontrasepsi hormonal $\leq 2$ tahun.

Teori menyebutkan metode kontrasepsi hormonal baik estrogen maupun progesteron dapat memengaruhi tekanan darah. Estrogen merupakan salah satu hormon yang dapat meningkatkan retensi elektrolit dalam ginjal, sehingga terjadi peningkatan reabsorbsi natrium dan air yang menyebabkan hipervolemi kemudian curah jantung meningkat dan mengakibatkan peningkatan tekanan darah. Progesteron dapat merendahkan kadar HDL-kolesterol serta meningkatkan kadar LDL-kolesterol, sehingga terjadi arterosklerosis kadar LDL-kolesterol tinggi dalam darah yang dapat menyebabkan penyempitan pembuluh darah dan retensi perifer pembuluh darah kemudian mengakibatkan peningkatan tekanan pada pembuluh darah (Hartanto, H., 2012)

Peningkatan tekanan darah pada wanita pengguna kontrasepsi oral disebabkan ekspansi volume karena peningkatan sintesis hepatik substrat renin dan aktivasi sistem renin-angiotensin-aldosteron. Kontrasepsi estrogen akan meningkatkan tekanan darah 3-6/2-5 mmHg. Sekitar 5\% wanita yang menggunakan kontrasepsi oral yang mengandung estrogen dan progesteron dalam jangka panjang mengalami peningkatan tekanan darah diatas $140 / 90 \mathrm{mmHg}$ yang didiagnosis sebagai hipertensi. Hipertensi terkait kontrasepsi terjadi pada wanita yang menggunakan kontrasepsi lebih dari 5 tahun dan individu gemuk (Mashitah, S.I dan Romdoni, R., 2015).

Kejadian hipertensi juga dilaporkan lebih tinggi pada wanita yang menggunakan kontrasepsi oral kombinasi (KOK), terutama wanita obesitas dan 
lebih tua. Sebuah penelitian kohort prospektif pada hampir 70.000 perawat selama 4 tahun (1989-1993), menunjukkan resiko relatif hipertensi 50\% lebih tinggi pada yang sedang menggunakan kontrasepsi oral dibandingkan dengan mereka yang tidak pernah menggunakan dan 10\% lebih tinggi dibandingkan dengan mereka yang pernah menggunakannya, bila dosis estrogen pada KOK naik dua sampai tiga kali lipat lebih besar dibandingkan saat awal menggunakannya (Mashitah, S.I dan Romdoni, R., 2015).

Kontrasepsi oral kombinasi meningkatkan tekanan darah rata-rata 5/3 mmHg, sehingga pada sebagian kasus mengalami hipertensi ringan dan hipertensi berat bahkan menyebabkan kerusakan ginjal yang irreversibel. Tekanan darah meningkat dengan cepat hingga berbulan-bulan atau bertahun-tahun setelah penggunaan awal pil kontrasepsi oral kombinasi. Saat kontrasepsi oral dihentikan, tekanan darah turun menjadi normal dalam 3-6 bulan pada sekitar 50\% pasien. Diantara wanita nulipara yang baru saja berhenti menggunakan kontrasepsi oral dan kemudian hamil, menunjukkan resiko terjadi hipertensi gestasional menurun namun resiko preeklampsi meningkat.

Guideliness dari American College of Obstetri and Gynekologi (ACOG) menyetujui penggunaan kontrasespi oral pada wanita hipertensi terkontrol, namun tidak disetujui pada wanita penderita hipertensi tidak terkontrol yaitu diatas 160/110 mmHg. Penggunaan kontrasepsi oral yang mengandung estrogen harus dibatasi pada wanita dengan usia >35 tahun, terutama dengan faktor resiko merokok, obesitas, atau hipertensi. Tekanan darah pengguna kontrasepsi hormonal harus termonitor dengan baik. Evaluasi kemungkinan adanya penyakit hipertensi sekunder, dilakukan minimal 3 bulan setelah kontrasepsi tidak digunakan (Pikir, S.B., dkk, 2015).

World Health Organization (WHO), tahun 2004 melalui Expert Working Group memberikan rekomendasi sediaan kontrasepsi oral kombinasi yang berisi estrogen $30 \mathrm{mg}$ dan progesteron $1 \mathrm{mg}$ atau kurang dipandang relatif aman dan dapat dijadikan alternatif bagi wanita dengan hipertensi namun masih ingin menggunakan kontrasepsi oral. Tetapi untuk wanita yang memiliki tekanan darah sistolik >160 $\mathrm{mmHg}$ atau tekanan darah diastolik $>100 \mathrm{mmHg}$ dan wanita dengan hipertensi 
disertai penyakit pembuluh darah tidak diperbolehkan menggunakan kontrasepsi oral kombinasi (Pikir, S.B., dkk, 2015).

Dengan diketahuinya beberapa faktor yang dapat menyebabkan hipertensi, dapat diupayakan beberapa strategi pencegahan penyakit. Pencegahan penyakit hipertensi dapat dilakukan mulai dari level primodial, primer, skunder, dan tersier. Pencegahan primodial bertujuan menghindari terbentuknya pola hidup sosial ekonomi dan kultural yang diketahui mempunyai kontribusi untuk meningkatkan resiko penyakit. Pencegahan primer bertujuan mengurangi insidens penyakit dengan cara mengendalikan penyebab penyakit dan faktor resiko. Pencegahan sekunder bertujuan menghentikan proses penyakit lebih lanjut dan mencegah komplikasi. Pencegahan tersier bertujuan menurunkan kelemahan dan kecacatan, memperkecil penderitaan dan membantu penderita-penderita untuk melakukan penyesuaian terhadap kondisi yang tidak dapat diobati lagi.

Ada beberapa upaya pencegahan primodial pada penyakit hipertensi, antara lain dengan membentuk sebuah kebiasaan beraktifitas fisik, berolahraga dan meningkatkan konsumsi buah dan sayur di masyarakat. Beberapa strategi pencegahan primer yang dapat dilakukan antara lain dengan menghindari pemakaian kontrasepsi hormonal dalam jangka waktu yang lama. Pencegahan sekunder dilakukan dengan cara memberikan pengobatan yang adekuat untuk mencapai target Tekanan darah, memastikan kepatuhan dalam menjalani program pengobatan, melakukan deteksi dini kerusakan organ target dan resiko kardiovaskuler sejak awal pengobatan hipertensi, menghentikan pemakaian alat kontrasepsi hormonal dan mencari alternatif kontrasepsi yang meminimalkan resiko hipertensi. Pencegahan tersier dilakukan dengan mengupayakan pendekatan interdisiplin terhadap tatalaksana kerusakan organ target yang dilakukan di rumah sakit rujukan.

\section{SIMPULAN DAN SARAN}

Ada hubungan penggunaan kontrasepsi hormonal dengan kejadian hipertensi pada wanita usia reproduktif $(p=0,002)$. Demikian juga dengan $\mathrm{OR}=5,7$ menunjukkan bahwa wanita usia reproduktif beresiko mengalami hipertensi 5,7 kali 
lebih besar jika wanita usia reproduktif menggunakan kontrasepsi hormonal dibanding yang tidak menggunakan kontrasepsi hormonal. Disarankan kepada wanita usia reproduktif agar membatasi pemakaian awal kontrasepsi hormonal dan lebih memilih kontrasespsi non hormonal ataupun kontrasepsi alamiah. Kepada pria atau suami agar lebih berpartisipasi menjadi akspetor KB karena alat kontrasepsi yang tersedia untuk pria tidak menimbulkan efek samping secara kesehatan. Untuk wanita usia reproduktif yang menggunakan kontrasepsi hormonal agar tetap melakukan monitoring tekanan darah secara rutin minimal 3 bulan pasca penggunaan kontrasepsi hormonal dan segera menghetikan pemakaian kontrasepsi hormonal jika mengalami hipertensi.

\section{DAFTAR PUSTAKA}

Hartanto, H. (2012). Keluarga Berencana dan Kontrasepsi. Jakarta: Pustaka Sinar Harapan.

Isfandri, S. (2015). Penggunaan Kontrasepsi Hormonal dan distress Emosional Sebagai Kontributor Hipertensi Perempuan Indonesia: Tinjauan Perspektif Gender. Bal. Peneliti. Kesehatan, 43 (1)

Kemenkes RI. (2013). Infodatin Hipertensi. Jakarta: Kemenkes

Kemenkes RI. (2013). Laporan Nasional Riset Kesehatan Dasar (RISKESDAS) Tahun 2013. Jakarta

Kemenkes RI. (2015). Profil Kesehatan Indonesia Tahun 2014. Jakarta

Lemeshow, et al. (1997). Besar Sampel dalam Penelitian. Yogyakarta: Gajah Mada University Press.

Lestari, P.I.; Wagiyo, Elisa.(2013). Hubungan Antara Lama Penggunaan Metode Kontrasepsi Hormonal dengan Kejadian Hipertensi. Skripsi. Program Studi S1 Keperawatan STIKes Telogorejo Semarang

Manuaba, I.G.B.(2012). Memahami Kesehatan Reproduksi Remaja. Jakarta: EGC

Mashitah, S.I dan Romdoni, R. (2015). Hipertensi pada Wanita dan Kehamilan. Surabaya: Badan Penerbit dan Percetakan UNAIR.

Moser, A.K.; Agrawal, S.; Smith, G.D.; Ebrahim, S. (2014). Socio-Demographic Inequalities in the Prevelance, Diagnosis and Management of Hypertension 
in India: Analysis of Nationally-Representative Survey Data. PLOS ONE. Published online: January 2014

Murayama, M.; Matsunaga, A.; Tangbanleukal, L.; Tantawiwat, S.; Ohtsuka, R., (2013). Effects of Oral Contraceptive use on body mass index and blood pressure among female villagers in North-East Thailand. Cambridge University Press Printed in the United Kingdom. Published online: April 2013

Nojomi, M.; Morrovatdar, N.; Davoudi, F.; Hosseini, S. (2013). Contraceptive use by Iranian women with hypertension, diabetes or obesity. Eastern Mediterranean Health Journal. Published online: 17 Mei 2013

Olatunji L.A dan Saldove A.O. (2012). Effects of Oral Contraceptive use on body mass index and blood pressure among female villagers in North-East Thailand. Cambridge University Press Printed in the United Kingdom. Published online: April 2012

Pangaribuan, L dan Lolong, B.D. (2015). Hubungan Penggunaan Kontrasepsi Pil Dengan Kejadian Hipertensi pada wanita usia 15-49 tahun di Indonesia tahun 2013 (Analisis Data Riskesdas 2013). Published online: 3 Juni 2015

Pikir. S.B.; Aminuddin, M.; Subagjo, A.; Dharmadjati, B.B.; Suryawan, I.G.R.; Eko, J.N.P. (2015). Hipertensi Manajemen Komprehensif. Surabaya: Badan Penerbit dan Percetakan UNAIR.

Rotermann, A.; Bouanani, N.E.; Mekhfi, H. (2015). Contraceptive use by Canada Women with Hypertension, Diabetes or Obesity. Eastern Mediterranean Health Journal. Published online: 17 Mei 2015

Saifuddin, A.B. (2006). Pelayanan Kesehatan Maternal dan Neonatal. Jakarta: Yayasan Bina Pustaka Sarwono Prawirorahardjo.

White, K.; Potter, J.E.; Hopkins, K.; Amastae, J.; Grossman, D. (2013). Hypertension among oral contraceptive users in El Paso, Texas. Mehary Medical Collage Journal of Health Care for the Poor and Underserved. Published Online: 2013 